\title{
NARCISSISM AS CLINICAL AND SOCIO-CULTURAL PHENOMENON
}

Elena T. Sokolova

Lomonosov Moscow State University

Moscow

Basing on the theoretical analysis and personal longstanding research, the author offers general characteristics of narcissism, delineates the relations between the disturbances of identity structure, regulatory mechanisms, cognitive styles and modes of interpersonal cognition, which allows predicting a wide range of psychic and behavioral disorders. It is shown that the phenomenon of narcissism has a bio-psycho-social causation, and that the contemporary technological glut as well as the expansion of consumerist values give new stimuli for the development of narcissistic and perfectionist personality trends.

Keywords: narcissism, consumerist values, perfectionism, body as the object of metamorphoses of self, manipulativeness in communication, compliance, psychotherapy, cognitive style, alexithymia, defense mechanisms, coping, autodestructiveness.

...inverted upon itself.

L. Durrell, Justine

\author{
And therefore, since I cannot prove a lover \\ To entertain these fair well-spoken days, \\ I am determined to prove a villain... \\ W. Shakespeare, Richard III
}

A surge of interest in the problem of narcissism in the psychological science and practice is stimulated by the development of the so-called culture of narcissism with its own values, including consumerism. Just as the contemporary consumerist society loses its integrity and becomes more secular and individualized, so does the self of an individual undergo a process of fragmentation due to excessive preoccupation with egocentric interests, emotional absorption in oneself and abundance of the ways of 'satisfaction' suggested by the social institutions (Bauman, 2002; Lipovetsky, 2001). 
Narcissism is an international phenomenon, but we cannot deny the role of cultural specificity and national mentalities. For example, it is said about Russians, that they easily set excessive goals and equally easily become demotivated when their dreams do not come in any measure true (Korovkin, 2008). For us 'half-full glasses' do not exist, we are maximalists and perfectionists. A native narcissist demonstrates constant spiritual struggle between conformity and respectability of his inner 'bourgeois' and destructive negativity of his inner 'anarchist': part of his spiritual aspirations is associated with a burning desire to be an exemplary social individual, and he readily absorbs clichés, suggested by mass-, pop- and glam-culture; but the other guise of a narcissist is, on the contrary, aimed at destruction of every basis, sabotage, transgression and search for new ways of demonstrating his 'otherness' and utter individualism.

\section{General characteristics of narcissism}

Preoccupation with high self-esteem maintenance and 'self-improvement' compels a narcissist to be constantly involved in the activity of altering his or her own self. Personality becomes a sui generis 'biographical constructor' (Beck, 2000), which is transformed and arbitrarily assembled under the influence of various social roles, constantly changing recommendations of scientists and experts, journalists and popularizers, healers and clairvoyants. "Slimming with the Rublev pill we look younger," "Magnificent sex - regularly, success with women - always!", "I deserve it!" are the examples of some cultural stereotypes, widely exploited by glamorous mass-media. The suggestive influence of such stereotypes and their active adoption in the simplified cognitive structures of consciousness and worldview of an individual create and sustain the unrealistic urges for 'transgression' - the illusory feeling of omnipotence that overpasses all the borders: of sex (one may change it operatively), time and age (stem cells rejuvenate), evident and imaginary body defects (the potential of cosmetic surgery and transplantology is unlimited).

The mass media are placed at the service of narcissistic goals; they make a fetish of the ideal, well-shaped, ever-young, sexy and slender body. The bodily well-being itself becomes a synonym of success, life opulence, happiness and self-satisfaction. The worship of excellence turns into a mass, feverish pursuit of an ideal, into a new mania, a dependence that may be called 'narcissistic perfectionism.' With this pursuit of pres- 
tigious attributes of influence and power one attains identification with the omnipotent part of one's own self, but simultaneously it awakens the opposite states: painful discontent with oneself because of the jealous and envious rivalry with the object of idealization, loss of self-confidence, questioning the justifiability of one's own existence. Therefore, the other side of the coin when striving for excellence (unattainable in reality) in modeling one's own body, arrangement of one's dwelling, organization of business or family is bitter disappointments, the so-called narcissistic wound due to inadequacy of fantasies of one's omnipotence and superiority.

A contemporary man gradually loses the inner certainty of rectitude, becomes 'chameleonic' at the core; he professes moral relativism, he is ready to change bodily covers as well as worldviews; his sense of self is diffuse, vague and uncertain, while the expansive limitlessness of selfidentity is driven by the desire to try everything, take part in everything, make it everywhere, be spotted, hang out. In psychoanalysis, people, whose life has lost its relish, is full of boredom and fuss, and all the efforts are concentrated on maintaining self-respect, are called narcissistic (Freud, 1991; 2002; Henseler, 2001; Green, 2001). The essence of narcissistic self-affirmation is also the incessant polishing of manipulations that make others pay attention to the 'shiny façade' and cease to notice the horrifying emptiness, misery and viciousness of the self. To give others (and oneself) the impression of excellence and superiority ('grandiosity') while experiencing the deep-rooted fear of disavowal of the 'naked king,' of helpless impotent self, - this is the core of the motivation of a narcissist and the secret of his absorption in everything exterior: body image, dwelling place, glamorous company of celebrities and boy-/ girlfriends, profusely stamped in fashion papers or TV shows. The stronger the anticipation of shame for the potential disgrace of disclosure, the subtler the wiles and manipulations, the more 'glamorous' the façade and the image of the outwardly presented social self might be (Kilborne, 2007). "By controlling how we appear to others," one of the researchers of this phenomenon notes, "we try to control how we appear (and feel) to ourselves" (Kilborne, 2007). As to the needs for all-embracing control and unlimited power, they are one of the deepest and the most unconscious sources of narcissism.

The demands of unlimited excellence as a rigid inner imperative (a rudiment of trustfully and uncritically introjected infantile dependence 
on steep parental expectations) along with the fundamental unattainability of an ideal grow into constant depreciatory criticism of self and others and lead to the inability to derive any pleasure from life while putting up with the natural limitation of human existence. The trouble with these people is that they claim to be exceptional in everything, even in the severity of their own sufferings, so that they actually 'exclude' themselves from the human community; in fact, they are outcasts.

They are constantly tormenting themselves, they are 'masochists,' they are unbearable for others. In everyday life it is usually said that these people lack courage to bear with fortitude not only extreme, but even ordinary life hardships. They appear too fragile and maladjusted to life, and in this sense others feel uneasy, as if risking to bring about an accidental threat to them, feeling like an 'elephant in a china shop.' Still it is just one guise of a narcissistic duality. The dissonant personality traits are intertwined in them in a fanciful way: the excessive dependence on the attention and praise of others, which make them 'bloom, and the emphatic distance, haughtiness, and coldness. They are hardly predictable and prone to mood swings; they feel difficulty in coping with their emotions, especially angry and boisterous ones, and most often they have to hide or mask their genuine feelings and passions; they are highly ambitious and oversensitive, but at times they are tactless and even cruel; with the slightest disappointment their admiration and idealization may turn to disdain and depreciation. They desperately need attention and support, 'strokes' for their vanity, but nevertheless they are rarely able to overcome their hubris, to ask for help and even more rarely - to accept it with genuine gratitude; bonds of attachment are both tempting and frightening them.

Occasionally they show extraordinary generosity and benevolence, but they are unaware of their own spells of sharp envy and insatiable avarice; what they have received is never enough and it often slips through their fingers. It is difficult to rely on them in joint activity, they may genuinely dream of being useful, at times they may make grandiose plans and believe in their ability to perform miracles (anything less impressive does not tempt them), but the smallest failure may discourage them to an extent that they feel absolutely incapable of functioning; they lack willpower to pursue their goals in a dogged and consistent way; instant and momentary mobilization with subsequent exhaustion and apathy is more characteristic of them. 
They prefer to live a risky life, to balance on the razor's edge, ignoring the dangers, surmounting illnesses, disregarding limitations - as if they are above them; the rules of community life and standards of ethics seem unbearable and meaningless to them. They often feel boredom and emptiness in their lives, they do not see its joy and value, and altruism is alien to them. With all their sensitivity, at times they need super strong and even painful stimuli (and they quickly become their slaves) in order to awaken any sensations in themselves and revive some zest for life for a moment. Experiencing intense suffering and at the same time being insensitive and callous, they make others suffer; they are alternately the victims and the torturers. Overall, they have everything - extremes and contradictions, complexities and intricacy. They have got an inexplicable charm of perfection and depravity, they are haloed with mystery; they arouse anything but indifference in others. They annoy, shock, evoke admiration and terror, attract and repulse at the same time; their close others do not love and appreciate them so much as feel compelled to bear with them or pity them; in social life they take extreme positions: they are either outcasts or stars, tyrants with delusions of grandeur and impeccability.

The prevalence of various versions of 'disintegration of self' and destructivity in contemporary society makes us take these phenomena of narcissism and concomitant perfectionism as borderline cases between norm and clinical psychopathology, as a sort of 'socio-cultural pathology' of self-identity. The forms of narcissistic destructiveness are manifold; like a cancerous growth, they penetrate all spheres of life activities and are manifested in perfectionism, in negativistic and hostile attitude toward oneself and others, and in corresponding forms of social practice, as overindulgence in food, alcohol or drug abuse, workaholism, addiction to information technologies, sex, systems of spiritual and bodily 'self-improvement', bathing habits and cosmetics, fitness, plastic surgery, - the list of objects is endless. "Just as," H. Kohut notes, "it is the under-stimulated child, the insufficiently responded-to child, the daughter deprived of an idealizable mother, the son deprived of an idealizable father, that has now become paradigmatic for man's central problem in our Western world, so it is the crumbling, decomposing, fragmenting, enfeebled self of this child and, later, the fragile, vulnerable, empty self of the adult that the great artists of the day describe - through sound and word, on canvas and in stone - and that they try to heal. The musician 
of disordered sound, the poet of decomposed language, the painter and sculptor of the fragmented visual and tactile world: they all portray the breakup of the self and, through the reassemblage and rearrangement of the fragments, try to create new structures that possess wholeness, perfection, new meaning" (Kohut, 2002).

\section{Phenomena of body narcissism}

Concern about the body self plays a special and overwhelmingly important role in the inner world of a narcissist: the value of beauty, appearance, physiological functions and somatic health is exaggerated, and the estimation of their actual state is never satisfying.

I, that am curtail'd of this fair proportion, Cheated of feature by dissembling nature, Deformed, unfinishid, sent before my time Into this breathing world, scarce half made up, And that so lamely and unfashionable That dogs bark at me as I halt by them...

S. Freud analyses this famous program monologue of Richard the Third and notes: "What the soliloquy thus meant is: "Nature has done me a grievous wrong in denying me the beauty of form which wins human love. Life owes me (emphasis added - E.S.) reparation for this, and I will see that I get it. I have a right to be an exception, to disregard the scruples by which others let themselves be held back. I may do wrong myself, since wrong has been done to me.' ... Richard is an enormous magnification of something we find in ourselves as well. We all think we have reason to reproach Nature and our destiny for congenital and infantile disadvantages; we all demand reparation for early wounds to our narcissism, our self-love" (Freud, 2002).

They deeply depend on the standards of perception of corporeality and suffering decreed by society and culture, and when they fall short of them, in reality or in imagination, this turns the image of bodily self into the focus of an individual self-will; the image of bodily self is subjectively distorted even more than the perception of external objects of reality. The feedback, which is provided by photos, mirrors, video shooting, does not prevent the distortion of the physical and bodily image of 
the self under the influence of motivation, somatic state and mood, success / failure (Sokolova, 1989; 1995).

The body image of people under the influence of heavy dependence on intrapsychic states of content / discontent as well as on demands and opinions of their social circle (they impulsively identify themselves with it) is especially prone to pathological fluctuations. In this case we may state the presence of a syndrome of 'blurring of the boundaries of self,' which suggests high stress resistance generally and victimization in particular; I have found it in people with borderline-narcissistic personality organization with especially vulnerable self-esteem: prostitutes with venereal infections, survivors of physical and sexual assault, food addicts, individuals with suicidal tendencies and consumers of the services of plastic surgery (Sokolova, 2007; Sokolova \& Baranskaya, 2007; Sokolova \& Ilyina, 2000; Sokolova \& Korshunova, 2007). The boundaries of the body image of the self are too permeable and do not manage their 'maternal' functions of a protective barrier against outer violence and unbearable inner overpressure. The inner space of bodily self is prone to metamorphoses: it forfeits temporal and spatial stability - it either extends immensely (narcissistic expansion) or 'flattens', loses its volumetric properties, its full-fledged sensuality, devitalizes, and discloses subjectively experienced lifelessness and emptiness.

Narcissistic personalities seek excellence everywhere, so they show impetuous perfectionism in bodily realm as well: being hypochondriacs, they nevertheless incessantly care about their health, take newfashioned (costly or exotic) medicines and charm-like devices, unceasingly 'improve' themselves, wearing themselves out with various diets and physical exercises. They become frequenters and fervent admirers of fitness-clubs, beauty salons, finding artificial pleasures in various manipulations with their bodies, which never satisfy them though. They are ready for any plastic surgery (and go through it again and again), only to gain more perfect looks. This passion often turns into an uncontrollable mania, and manifests itself in an overdependence of self-attitude on body states and manipulations with body. Hence the apparent psychopathology of their everyday life - the irrepressible passion for everything that may generate and maintain the feeling of self-perfection: from expensive perfume to exotic diets, from fitness to countless plastic operations. We may reduce this example to a paradox, which has been formulated by S. Lem in one of the novels: Can an astronaut, a survivor 
of many cosmic catastrophes, for whom the surgeons make prosthetic appliances of many (eventually almost all) body parts and organs, be considered a selfsame personality?

The worship of one's own bodily self and its deification is just one 'part' of narcissistic self-identity, the inverse 'part' consists in the affective complex of chronic discontent with oneself (Kilborne, 2007). People with the so-called food addictions experience obsessive and unceasing desire to lose weight in order to fit the ideal bodily sizes and contours, but they never feel fully satisfied with the result achieved and struggle with the subsequent disappointments by indulging in uncontrollable binge-eating. However, implemented in self, a model body image turns into the 'tyranny of ought-to' with ruthless self-reproaches, disdain, self-torment, and ends in the loss of wholeness, in the annihilation of identity, the feeling of emptiness. Many clinical observations show that girls with the syndromes of anorexia / bulimia are characterized by gross alteration and splitting of the body image of the self. They are virtually unaware of the way they are exhausted by their lengthy fast, they do not realize how emaciated and unattractive they are; both physiologically and in appearance they lack femininity, but even in the state of mortally dangerous cachexia they still see themselves as 'insufficiently skinny', and with the slightest weight gain - 'fat' (Sokolova, 1989; 1995). One of the patients of the famous American psychiatrist Hilda Bruch could not spot the difference between the two photos of herself, though in one of them she weighed 30 kilos heavier. Another patient confessed that she could see how emaciated she had become only when she was in front of the mirror, but as soon as it was out of sight, she used to feel she was fat (Bruch, 1979).

People with such an illness lack personal system of inner appraisals, and in an absolute confusion they literally 'crouch' to the appraisals of other people, as a rule, to the insights and values adopted from some glamorous sources. In experts' opinion, food addiction is merely a particular case of consumerist tastes, which would hardly be possible and sensible to catalogue, as their objects are derived from material culture and human individual history, but the psychological mechanism of addiction remains uniform. The absence of representations of a secure, constantly supporting maternal object in the inner world makes them obsessively look for it outwards and find surrogate consolation in ar- 
tificial objects of a symbiotic ('narcotic') attachment-dependence, only 'sticking' to which they are able to feel themselves (Fonagy, 2002; McDougall, 2007).

The attitude of a narcissist toward him-/ herself and others can be described by a 'complex of the boy Kai' from the well-known fairy-tale by H.C. Andersen: a piece of ice got into the eye of this character and deprived him of compassion. This is a phenomenon of estrangement from one's own self, of callousness, emotional coldness, that embraces all spheres of mental life and manifests itself in fading of sensations and spiritual poverty, in specific affective flattening. As one patient puts it: "I understand what I have to feel, but I do not feel it," - the rational and the sensually emotional is separated in their lives. Similar to the heroine of the film "The Pianist" directed by M. Haneke, such people seem to be insensitive to pain, they feel a strong desire to hurt themselves physically, but even this does not revive their ability to feel, they remain strangely alienated, detached observers of their bodily functions. At times they identify themselves with this or that organ or body part, but they are unable to create a holistic and full-blooded notion of themselves which would not be devitalized and fragmented. They can easily and unemotionally let others use their bodies (easiness of prostitution), and are also prone to manipulative interpersonal relationships (Sokolova, 1995; Sokolova \& Ilyina, 2000).

They are unfamiliar with authentic intimate relationships, in love and sex they first of all seek acknowledgement of their uncommonness and superiority over their partner, rather than trust and unity, - they confuse deep attachment with stifling dependency and flee from it (Bruch, 1979; Kernberg, 2000; Green, 2001). The opulence, the impetuousness and the exotic nature of their fantasies (often characterized by sadomasochism, fetishism and various other perversions) are combined in a bizarre way with their real, emotionally emasculated relationships, with the technicality and mechanicalness of sex. They are lonely even here, as a matter of fact, they do not need a sex partner, or this partner is easily replaceable. Apparently, this is the reason why the role of Casanova looks so attractive to them, as well as sexual omnivory and indiscrimination (promiscuity), where masturbation, fetishism and homosexuality are practically equated in their estrangement both from the self and the object of the feelings, pierced by coldness and emptiness. 


\section{Narcissistic alexithymia}

It is hard for narcissists to clothe their feelings in words; a significant part of their life is carried on nonverbal and presymbolic levels, in dim, slightly conscious, but mighty in their affective charge sensations and 'drives-inclinations', and mental ill-being almost always manifests itself under the mask of somatic illness, hypochondria and somatoform depressions. For example, patient M., who had been suffering of recurrent miscarriages for 8 years, in the process of psychotherapy came to realize that the invincible vomit and nausea from the concrete psychosomatic symptom (toxemia of pregnancy) that tormented her had long ago overgrown into the stereotypic and generalized reaction to "violence and villainy of life," that "broken" relationships with people had followed her from her early childhood, that all the period of muteness of her self she had been "pregnant with hatred" (Sokolova, 1995).

As it was said before, corporeality itself is in 'focus' of a discriminative, deeply biased and heightened interest of a narcissist, it is the core of his / her self-attitude, it exceeds greatly both interest in other aspects of the self and in other people (Freud, 1991; 2002). The specificity of narcissistic self-identity as a whole, with all its splitting, fragmentariness, and predominance of unrealistic idolization / devaluation is reflected in the perception of physical and gender self. The inner inconsistency of representations of corporeality (which evolves due to splitting of the sensual and symbolic levels of self-consciousness and as a result of concrete and situational cognition) causes the polarity of emotional attitude to one's bodily life that ranges from haughty exhibitionism and perfectionism to a sort of body masochism, extremism and 'self-terrorism.' It is a question of exaggerations, almost caricature superfluity, with the help of which the narcissistic personality tries to achieve and maintain attributes of bodily perfection and in the case of a failure he / she sadistically punishes him-/ herself.

An actual image of bodily self is exceptionally sensitive to the influence of past negative emotional experience and is merged with representations of the so-called primary objects: the infantile images of mother and father figures. F. Kafka, remembering his childhood, wrote with bitterness and shame about the permanently remaining sensation of his insignificance in comparison with the father figure, mighty and impeccable in its immediate and 'dismal' corporeality that blocked his 
speech and made intimacy inaccessible and unattainable. In his mature years he was still suffering from the idea of his physical unattractiveness and avoided intimate relations, to the end of his life he experienced emotional isolation and 'muteness.'

\section{Body as an object of perfectionistic-narcissistic manipulations and metamorphoses}

A contemporary man desperately mourns the loss of youth and attractiveness, the temporariness of the flesh of life, he is prone to antisocial ideology, and he shares ideas of archaism and inexpediency of a clear and in some sense limited self-determination; the dreams of omnipotence and permissiveness are dear to him. As a result, there is a search for alternative forms of behavior and multiple metamorphoses of identity that hypertrophy the sense of proper uniqueness (Bauman, 2002), but increase the risk of splitting and diffusion of identity. The paradox is that narcissists are deeply individualistic in their nature and at the same time they are oriented outwards, toward others; the cutting-edge technologies of 'self-presentation' and 'charisma-making' (a biting remark of V.P. Zinchenko) are highly appreciated and in great demand in the contemporary society, so they additionally provoke and sustain this human weakness, and wittingly unwittingly, they promote the flourishing of the culture of depersonalization and the culture of 'pseudo.'

Nowadays, with the speeding development of the market of social services that allows arbitrary simulation and transformation of appearance while the body is considered a subject of trade, the value of which may and should be increased in every possible way, the aesthetic surgery starts to be used along with other innovational technologies for the satisfaction of needs that 'sustain' the public image of self. The urge for self-development is out of question here, on the contrary, this is the case of obsessive, irrational desire for escape from one's own (alive, authentic, but not faultless) self and the magical discovery of another bodily self instead of it, which would be free of shortcomings and weaknesses, but which would be fictitious and unrealistic.

The situation is created, which provokes a radical transformation of self-consciousness and ethics of the human species as a whole, for example, when the body becomes an easily altered or even replaced object. Body and gender cease to be a basic identity and turn into just one of the 
possible identifications of the human self that depend on social-cultural factors - status, financial possibilities, fashion, etc. All of this can result in deformations and loss of self, making one not only ultimately impressionable, but imprudently 'omnivorous,' and creating various forms of 'social pathology.' Among them is the narcissistic perfectionism with its pretensions to limitlessness, omnipotence and 'trans-humanity', disdain for nature with its natural limitations, and conviction of the omnipotence of technologies, their fetishization.

The above-noted personality traits may be illustrated by our study (Sokolova \& Baranskaya, 2007): a considerable part of patients in aesthetic surgery has narcissistic dynamics of motivation: panic fear of loss of attractiveness, unbearable shame about caducity and flabbiness, about the ineptitude of the body image to perfectionistic socio-professional and cultural standards. They are inclined to use plastic surgery as an archaic defense mechanism - an unconscious bodily reaction to the unbearable sense of shame. As in Russian fairy-tales, they dream that peeling, lifting, etc, like some fabulous boiling milk, will help them to throw off the 'snakeskin' of the old age, that they will 'hit the floor' and turn into a gracious lad or a bonny lass, and the Firebird will be waiting for them in the form of new romantic relationships.

The typical consumers of these services are women (lately, men as well) who hold responsible positions in administration and management, who are show-business or movie stars, divorced or unmarried, as well as people with hypochondriac concerns, who often turn for medical help. Usually they have got a highly dependent personality pattern, are suggestible, devoid of clear internal cues and prone to social conformism. They automatically and uncritically interiorize values that are actively promoted by the mass-media and socio-cultural stereotypes of unacceptability of any signs of ageing and imperfection, which force people to 'salutary' surgical intervention, allegedly able to deliver them from any life problems.

Indeed, positive changes in physical appearance improve psychological state, enhance self-esteem and self-confidence. But independent researchers point at the psychological side-effects of a surgical intervention, such as sleep disorders, anxiety, symptoms of depressive states and nonspecific somatic complaints. Even at the best possible outcomes of operations many patients still feel disappointed and deceived, as the real life situation or intimate interpersonal relationships have not been 
changed - after all, contrary to their expectations, the alterations of appearance do not provide them with new inner resources.

Let us recall that the self of a narcissistic personality, unsupported by significant others, becomes 'bad,' and the disappointments experienced are perceived as a dreadful 'narcissistic wound,' as a complete life catastrophe. Those who turn for help to aesthetic surgery naively believe that after their transformation, with a new body image they become insured against unfaithfulness, parting and other disappointments. Insofar as they achieve inner conflict 'resolution' largely through the apparent external alterations, a narcissist is a baby-like 'materialist' - the symbolical working out of the intrapsychic conflicts is hindered or blocked. Nothing can satisfy or console him or her, except the immediate and the desired change of the particular 'unbearable' circumstances. If they cannot manage to 'make' the situation or other people obey their wishes, then the situation should be ruined; so an impulsive act like an aesthetic operation as a narcissistic illusion of an instant discovery of the glorious future becomes an acceptable way of solving the problem. To emphasize: the motive is not a mere achievement of perfection, but the wish to dispose of one's own self, which is loaded with failures and disappointments, and to discover instead of it a new self which would be pure and unsullied like that of a child. But when, despite a successful operation, one still feels 'insufficiently satisfied,' the focus on a 'bad' part of the body does not go away, so one starts looking for a 'better' plastic surgeon and a 'better' clinic.

One of the significant markers of a 'narcissistic personality' is the predisposition towards the manipulative style of communication, the ambition to control others, including the doctor, the rejection of social norms and the opposition to the socially regulated behavior. The collaboration with doctors (compliance) of patients from the risk group is paradoxical and manipulative too (a combination of dependence and depreciation), it has undesirable outcomes in the form of anger, sabotage of medical recommendations, psychological pressure, devaluation of help, suicidal intimidations, legal claims. That is why the postoperative period is accompanied by the painful feelings of discontent with the results of the operation, by the narcissistic 'wreckage,' and backslides to the sense of self-inferiority, a peculiar depression of defeat. A physician becomes that character of a projection, who "betrays as all the others always do," inflicts a narcissistic wound, and hence, to punish him with blackmail or 
legal action is quite rightful. Manipulative-provocative behavior of these patients exhausts the doctor and contributes to his 'emotional burnout', shatters his professional self-respect and involves him in paranoid and litigious relationships.

\section{Narcissistic worldview and human relationships}

It is assumed in contemporary psychology that the coherent, integral and consistent worldview may develop in childhood and its stable functioning protects one from the rubs and worries of life only by virtue of a responsive attitude of a caring adult, i.e. inside the unique 'container' of the relationship of secure attachment (Fonagy, 2002). Thus, relationships between the child and the adult serve as 'space' that provides affiliating, nourishing and sustaining or, on the contrary, 'toxic', disabling and destructive environment, in which all the psychological functions are formed, including regulatory systems, cognitive abilities, language and symbolic means of processing of the 'unbearable' affective state. The 'working models of attachment' or 'representative models of object relationships' acquired in childhood (the variability of terms is imposed by the corresponding theories) are responsible for the unconscious dispositional readiness for a specific organization of actual interactions and for the influence on affective valence ('coloring') of perception, benevolent or hostile (Sokolova \& Korshunova, 2007). This context is orientating for our studies of the psychological regularities that determine the development, formation and functioning of cognitive structures, generalized-schematized conceptions of interpersonal relationships, mechanisms of affective regulation (defenses and copings), which function as the systemically organized attitudinal mechanism of social cognition or affective-cognitive style (Sokolova, 1995; 2002; Sokolova, Burlakova, \& Leontiu, 2001; Sokolova \& Ilyina, 2000; Sokolova \& Korshunova, 2007).

A personality style is a stable individual pattern of cognitive attitudes and schemes, along with configurations of attitudes toward self and significant others; it determines one's proneness to be oriented to the settled system of standards or to update it in a creative way in new, uncertain and critical situations. A style models the emotional relationships and the processes of social cognition; it determines success or failure of the human capacity to selectively generate and durably sustain trusting relationships with close ones, to enter into the relationships of respon- 
sible and equal cooperation. The communicative representations, vague, inadequate, deficient, hyperbolized and hyper-generalized, sometimes fantastic and occasionally subtly emotional and sagaciously precise may work as a consolation, a guide for action (as the leading strings for a child), but they may also constantly undermine self-confidence, lead to helplessness and to impulsive, dangerous and risky decisions.

Self-representation is unstable when the ability of rational and reflexive self-esteem independent of actual affective states and frustrations is deficient; it undergoes constant fluctuations and distortions. This 'seesaw' is characteristic of the borderline-narcissistic personality organization and is enabled by the emotional instability and the deep vulnerability of self-esteem, the 'grandiosity of self' along with the inability to mentalize and symbolize, and the predominantly psychosomatic mode of elimination and regulation of psychological traumas (the syndrome of alexithymia).

Are there any specific types of personality with heightened predisposition towards such manifestations of self-destruction as bodily selfmutilations, addictions, gender perversions, etc? The results of our studies show that the evaluation of cognitive dependence and differentiation of self-consciousness is a reliable predictor of behavior deviations and the relevant type of personality. However, it turns out that this is a complex relationship: both those who 'globalize', underestimate differences, exaggerate resemblance, and those who over-differentiate, overestimate differences and smooth out resemblance experience big difficulties when they try to integrate ('gather') themselves. People with the lowest level of cognitive differentiation, semantic 'implementation' of selfconsciousness and high field-dependence reveal uncertainty, vagueness, temporary instability of the system of representations, low level of generalization and coherence of the concept of self and significant others into an organic whole. A typical configuration of the undifferentiated and globalized defenses (projective and introjective identification) strengthens the symbiotic dependence in relationships, the lack of 'selfhood' and wholeness of self-identity, the splitting of relationships into 'good' loving and 'bad' aggressive parts, the confusion of interpersonal boundaries, the proneness to diffusive anxiety, the impulsive motor reacting of the 'unbearable' emotions in deviant behavior.

Besides, cognitive field-dependence implies over-concrete thinking, narrowing of possibilities of transcendence of the actual, the empirical 
and the immediately given, by means of detached thinking or reconstructive imagination, a dream; it hinders the anticipation of the future, the metaphorical reconstruction of things missing or lost, and because of that it significantly lowers personality resources for recovery and fuels the state of chronic 'emotional hunger', constant discontent. Low differentiation ('cognitive simplicity', lack of analytical means and regulation) manifests itself in the inability to notice subtle differences and changes, to distinguish what is primary from what is secondary (especially in the sphere of social relationships and self-perception), in 'globality' and 'dichotomy' of judgments and ideas, anti-dialecticism of cognition as a whole.

In psychotherapy people of this kind are referred to as 'difficult', their cognitive abilities provoke generalized resistance to treatment, sabotage of cooperative relationships (insufficient compliance), and impose limitations on the ability to feel relief and at least partial satisfaction from words and mental transformations, not from actions or 'things.' The inclination to solve critical situations autodestructively is also found in people with the traits directly opposite to the above-mentioned ones with extremely high (but 'false') cognitive differentiation and excessive specification, but however, with mutual inconsistency and fragmentariness of the notions about self and others. While analytical operations of cognition are available to the individual, he or she lacks neutral reflexive position, consistency and self-control, but the main defect lies in the absence of selectivity and in the inability to synthesize (integrate) experience that has been fragmented by anxiety.

The mechanism of splitting and its derivatives: depreciation and superiority, preeminence and grandiosity, - are the backbone of the general configuration of defenses; they are conducive to rejection and destruction in the relationships with others. The parasuicidal behavior is activated in response to the narcissistic insults and 'betrayals' by others, the wreckage of narcissistic expectations and malignant shame, which is generated by the subjectively perceived total personal failure.

Thus, both types of people with the absolutely opposing and extremely pronounced traits of cognitive-affective organization show common basic defects of personality. Both complain of inability to experience pleasure, enjoy life, play, invent, find through insight new dimensions in habitual everyday things; they lose coherence and consistency of thinking as well. The analogy with the baby's indifference and the delay in cognitive devel- 
opment in response to the prolonged deprivation of maternal love and attention is quite appropriate here. The absence of the object in the reality, when it is not compensated by its sustaining symbolical representation in the inner world, leads to the irreparable loss of bonds - of emotional relationships with people, and the cognitive wholeness of mental representations. The world inside and outside of self appears in chaos and total uncertainty, out of spatial and temporal coordinates, without a possibility to be expressed in words, to gain certainty and 'core'; this definitely inspires confusion and global helplessness. The difficulty is that a patient by virtue of his or her global 'field-dependency' or equally global and exaggerated autonomy can hardly accept help through an empathic word, which implies the intermediate space of 'game,' 'dream', convention, created in therapy. In a certain sense he is too much of a materialist, not an idealist, he craves for the visible and 'material' dimension of life; the limitation of convention and the artificiality of the substitution cannot console him; but a psychotherapist can give him no more than that (Sokolova, 1989; 2007; Sokolova \& Ilyina, 2000).

Thus, the parasuicidal style of the personality pathology includes the specific intellectual defects that combine over-concreteness and overabstractness, disharmony in perception of self and others, and, correspondingly, paradoxicality and instability of relationships (from 'clingy' dependence with the loss of self to detachment and emptiness on the site of the significant other), a systemic shift toward the negative emotional coloring of the image of self and significant others, poorly specialized primitive defense mechanisms, the mixture of insufficiency and unselective redundancy of means of semantic and notional self-regulation of affective experience. The preponderance of splitting over integration leads to the fact that a traumatic emotional experience, be it a loss of the other or a narcissistic wound, chronically destabilizes the ability to experience and reflectively process crisis states, prevents preservation of one's own stable identity and retention of bonds with significant others.

As we can see, the phenomenon of narcissism goes far beyond the limits of the narrow clinical terms of reference; on the contrary, it reflects, as in a mirror, the universal problems, our problems, that we attribute to others in order to comfort ourselves. Today's cultural context with the predominance of pop-culture which is "hollow inside" like a Barbie doll (Goralik, 2005) appears to be the best environment for the generation and flourishing of narcissism. Global commotions and fi- 
nancial crises jeopardize our smug confidence in our ability to control the world, to foresee and preclude its impacts, but the challenging perspectives of high technologies promise fabulous exuberance and almost eternal life. The abundance of advertising creates the illusion of infinite opportunities, it promises, it seduces (Ulybina, 2004), and here we are, experiencing the joys of paradise - easily and without any effort. But a problem arises: if advertising and all the mass media are 'tender rapists', then who are we, so carelessly and boundlessly opening for them our souls and bodies?

\section{References}

Bauman, Z. (2002). Individualizirovannoe obŝestvo [The Individualized Society]. Moscow: Logos.

Beck, U. (2000). Obŝstvo riska. Na puti $k$ drugomu modernu [Risk Society: Towards a New Modernity]. Moscow: Progress-Tradiciâ.

Bruch, H. (1979). The Golden Cage: The Enigma of Anorexia Nervosa. Cambridge: Harvard University Press.

Fonagy, P. (2002). Točki soprikosnoveniâ i rashoždeniâ meždu psihoanalizom i teoriej privâzannosti [Points of Contact and Divergence between Psychoanalytic and Attachment Theories]. Zurnal praktičeskoj psihologii i psihoanaliza, 1. Retrieved from http://psyjournal.ru/j3p/pap.php?id=20020105

Freud, S. (1991). O narcizme [On Narcissism]. In S. Freud, Â i Ono. Trudy raznyh let. T. 1 [The Ego and the Id: Collected Works. Vol. 1] (pp. 107-133). Tbilisi: Merani.

Freud, S. (2002). Nekotorye tipy harakterov iz psihoanalitičeskoj praktiki [Some Character-Types Met with in Psycho-Analytic Work]. In V.M. Leibin (Ed.), Klassičeskij psihoanaliz i hudožestvennâ̂ literatura: Hrestomatiâ [Classical Psychoanalysis and Literature: An Anthology] (pp. 47-69). Saint Petersburg: Piter.

Goralik, L. (2005). Polâ̂ ženŝina. Mir Barbi iznutri i snaruži [Hollow Woman: The Inside and Outside Barbie World]. Moscow: Novoe literaturnoe obozrenie.

Green, A. (2001). Life Narcissism. Death Narcissism. New York: Free Association Books.

Henseler, H. (2001). Teoriâ narcissizma [The Theory of Narcissism]. In A.M. Bokovikov (Ed.), Ėnciklopediâ glubinnoj psihologii. T. 1 [Encyclopedia of Depth Psychology. Vol. 1] (pp. 463-483). Moscow: MGM-Interna.

Kernberg, O. (2000). Otnošeniâ lûbvi. Norma i patologiâ [Love Relations: Normality and Pathology]. Moscow: Nezavisimaâ firma "Klass."

Kilborne, B. (2007). Isčezaûsie lûdi. Styd i vnešnij oblik [Disappearing Persons: Shame and Appearance]. Moscow: Kogito-Centr. 
Kohut, H. (2002). Vosstanovlenie samosti [The Restoration of the Self]. Moscow: Kogito-Centr.

Korovkin, V. (2008). O naših polupustyh golovah [On Our Half-Empty Heads]. Novaâ gazeta , 38 (03.10.2008).

Lipovetsky, G. (2001). Ėra pustoty [The Era of Emptiness]. Saint Petersburg: Vladimir Dal'.

McDougall, J. (2007). Teatry tela [Theatres of the Body]. Moscow: Kogito-Centr.

Sokolova, E.T. (1989). Samosoznanie i samoocenka pri anomaliâh ličnosti [SelfConsciousness and Self-Esteem in Abnormalities of Personality]. Moscow: MGU.

Sokolova, E.T. (1995). Izučenie ličnostnyh osobennostej i samosoznaniâ pri pograničnyh ličnostnyh rasstrojstvah [The Research on Personality Traits and SelfConsciousness in Borderline Personality Disorders]. In E.T. Sokolova \& V.V. Nikolaeva, Osobennosti ličnosti pri pograničnyh rasstrojstvah ličnosti $i$ somatičeskih zabolevaniâh [Personality Traits in Borderline Personality Disorders and Somatic Illnesses] (pp. 27-206). Moscow: Argus.

Sokolova, E.T. (2002). Psihoterapiâ. Teoriâ i praktika [Psychotherapy: Theory and Practice]. Moscow: Akademiâ.

Sokolova, E.T. (2007). Fenomen psihologičeskoj zaŝity [The Phenomenon of Psychological Defense]. Voprosy psihologii, 4, 66-80.

Sokolova, E.T., \& Baranskaya, L.T. (2007). Kliniko-psihologičeskie osnovaniâ èffektivnosti èstetičeskoj hirurgii [Clinical and Psychological Grounds of Effectiveness of Aesthetical Surgery]. Socialnaâ i kliničeskâ̂ psihiatriâ, 3, 26-37.

Sokolova, E.T., \& Ilyina, S.V. (2000). Rol' èmocional'nogo opyta nasiliâ dlâ samoidentičnosti ženŝin, zanimaûsìihsâ prostituciej [Role of Emotional Experience of Violence for Self-Identity of Women Engaged in Prostitution]. Psihologičeskij žurnal, 21 (5), 70-81.

Sokolova, E.T., \& Korshunova, A.R. (2007). Affektivno-kognitivnyj stil' reprezentacii otnošenij Â-Drugoj u lic s suicidal'nym povedeniem [Affective-Cognitive Style of Representation of Relationships Self-Other in People with Suicidal Behavior]. Vestnik Moskovskogo universiteta. Seriâ 14 "Psihologiâ," 4, 48-63.

Sokolova, E.T., Burlakova, N.S., \& Leontiou, F. (2001). K obosnovaniû klinikopsihologičeskogo izučeniâ rasstrojstva gendernoj identičnosti [On the Grounds of Clinical and Psychological Research on Gender Identity Disorders]. Voprosy psihologii, 6, 3-17.

Ulybina, E. (2004). Reklama kak incestuoznaâ real'nost' [Advertisement as Incestuous Reality]. In V.A. Medvedev (Ed.), Russian Imago 2002: Issledovaniâ po psihoanali$z u$ kul'tury [Russian Imago 2002: Studies in Psychoanalysis of Culture] (pp. 465-493). Moscow: Agraf. 